University of Nebraska - Lincoln

DigitalCommons@University of Nebraska - Lincoln

USDA National Wildlife Research Center - Staff Publications
U.S. Department of Agriculture: Animal and Plant Health Inspection Service

2012

\title{
Phytochemical variation within a single plant species influences foraging behavior of deer
}

\author{
Bruce Kimball \\ USDA-APHIS-WS-National Wildlife Research Center, bruce.kimball@ars.usda.gov \\ John H. Russell \\ Cowichan Lake Research Station \\ Peter K. Ott \\ BC Ministry of Forests and Range, Research, Innovation and Knowledge Management Branch
}

Follow this and additional works at: https://digitalcommons.unl.edu/icwdm_usdanwrc

Kimball, Bruce; Russell, John H.; and Ott, Peter K., "Phytochemical variation within a single plant species influences foraging behavior of deer" (2012). USDA National Wildlife Research Center - Staff Publications. 1153.

https://digitalcommons.unl.edu/icwdm_usdanwrc/1153

This Article is brought to you for free and open access by the U.S. Department of Agriculture: Animal and Plant Health Inspection Service at DigitalCommons@University of Nebraska - Lincoln. It has been accepted for inclusion in USDA National Wildlife Research Center - Staff Publications by an authorized administrator of DigitalCommons@University of Nebraska - Lincoln. 


\title{
Phytochemical variation within a single plant species influences foraging behavior of deer
}

\author{
Bruce A. Kimball, John H. Russell and Peter K. Ott \\ B. A. Kimball (bruce.a.kimball@aphis.usda.gov), US Dept of Agriculture, Animal and Plant Health Inspection Service, Wildlife Services, \\ National Wildlife Research Center, and: Monell Chemical Senses Center, 3500 Market Street, Philadelphia, PA 19046, USA. - J. H. Russell, \\ BC Ministry of Forests and Range, Research, Innovation and Knowledge Management Branch, Cowichan Lake Research Station, Box 335 , \\ 7060 Forestry Road, Mesachie Lake, BC, VOR 2NO, Canada. - P. K. Ott, BC Ministry of Forests and Range, Research, Innovation and \\ Knowledge Management Branch, Box 9519, Station Provincial Government, Victoria, BC, V8W 9C2, Canada.
}

\begin{abstract}
To determine how black-tailed deer Odocoileus hemionus columbianus respond to phytochemical cues while browsing in heterogeneous phytochemical environments, we offered captive and free-range deer cloned rooted cuttings and seedlings of western redcedar Thuja plicata selected for varying monoterpene content. Black-tailed deer were thus allowed to browse among a controlled array of phytochemical cues in a series of experiments designed to evaluate foraging behavior at fine (within plot) and coarse (plot selection) scales. Within-plot diet selection experiments demonstrated that browse preference for individual western redcedar plants was a function of foliar monoterpene concentration. Individual plant palatability combined with momentary maximization foraging strategy promoted survival of heavily defended plants. Among-plot foraging experiments demonstrated that coarse-scale foraging preferences were strongly influenced by distributions of high monoterpene-containing western redcedar in available plots. Olfaction may play a significant role in both fine and coarsescale browse behaviors of deer as they employ a risk-averse foraging strategy.
\end{abstract}

Phytochemical and plant heterogeneity can influence foraging behavior at both fine (within-plot) and coarse (betweenplot) scales (Bee et al. 2009). Fine-scale preferences for specific plants (or specific plant parts) are constrained by herbivore anatomy and physiology and influenced by phytochemistry. On these bases, diet selection can manifest itself at greater scales as partial loss of plant genetic diversity or even entire plant species. Selective herbivory may also result in reduced plant population fitness when specific plant phenotypes are targeted by herbivores. It is well established that foraging decisions by vertebrate herbivores have the potential to significantly impact landscape-scale heterogeneity (Hobbs et al. 2003). In particular, ungulates have tremendous potential to alter ecosystem function via modulation of successional processes (Hobbs 1996). For example, relative cover and species richness between herbaceous and shrub species are drastically altered by large herbivores (Manier and Hobbs 2006). Likewise, plant heterogeneity exerts pressures back onto the herbivore. Spatial heterogeneity weakens density-dependent feedbacks to population growth, thereby enhancing growth rates (Wang et al. 2006). Thus, information regarding herbivore responses to variation in their foraging environments can be critical to understanding landscape dynamics.

Phytochemistry plays a significant role in herbivore diet selection as predicted by plant defense theory (Rhoades 1979). Mammalian forage preference for a variety of conifers has been linked to the repellent qualities of monoterpenes (Dimock et al. 1976, Farentinos et al. 1981, Bell and Harestad
1987, Reichardt et al. 1990, Bryant et al. 1991, 1992, Snyder 1992, Duncan et al. 1994, Estell et al. 1998, Kimball et al. 1998). The antifeedant properties of monoterpenes are thought to be mediated by their toxic properties (Bryant et al. 1991). Among other effects, monoterpenes inhibit acetylcholinesterase activity in mammals (Miyazawa et al. 1997) and may cause diuresis (Dearing et al. 2002). Herbivores limit intake of monoterpene-containing diets by reducing time spent feeding and/or by spreading feeding activity over extended periods to ensure that monoterpene intake does not reach a threshold dose (Dziba and Provenza 2008).

Plants are also comprised of primary metabolites (i.e. free and structural carbohydrates, proteins) as well as varying morphological characteristics that influence herbivore foraging. Herbivore diet selection is clearly influenced by nutrient content (Goralka et al. 1996, O’Reilly-Wapstra et al. 2005, Carmona et al. 2011). In fact, a recent analysis suggests that information regarding plant secondary metabolites (PSMs) does not reliably predict herbivore interactions with plants (Carmona et al. 2011). Notwithstanding these reports, a strong correlation between browse intensity and monoterpene concentration was recently observed from a genetic trial on southern Vancouver Island. In 1996, the British Columbia Ministry of Forests and Range, Research Branch established a western redcedar genetic trial to study rangewide adaptive patterns in fitness traits. In 2003, all trees were assessed for deer browse and foliar monoterpene content. It was possible to categorize the browse potential of many 
individual trees: non-preferred (no browse and high monoterpene content), preferred (high browse and low monoterpene content), or intermediate (low browse and average monoterpene content). These observations were consistent with other studies suggesting that monoterpenes influence diet selection in deer (Vourc'h et al. 2002a).

It was recently recognized that further work was needed to evaluate regulation of PSM consumption at various spatial and temporal scales (Iason and Villalba 2006). Toward this goal, we employed selective tree breeding and vegetative propagation techniques to produce western redcedar seedlings and cloned rooted cuttings with varying monoterpene concentrations. Cuttings and seedlings were maintained under identical conditions to reduce variation among primary metabolites. Tradeoffs between defense and primary metabolism are rarely detected for woody plants at the individual level (Koricheva et al. 1998). Carbohydrates respond predictably to environmental parameters such as light and nutrients, while terpenoid concentrations are not generally impacted by environmental promoters of primary metabolism and growth. Thus, breeding and propagation were employed to maximize monoterpene variation while resources were controlled to minimize nutritional variability among the test plants.

Here, we describe a series of experiments to monitor deer responses to experimental manipulations of western redcedar phytochemical foraging environments. We examined deer preferences of individual plants varying in monoterpene content within plots as well as among plots varying in distribution of high monoterpene-containing plants. Our objective was to determine how foraging decisions were influenced by phytochemical variation at fine and coarse scales.

\section{Material and methods}

\section{Plant experimental material}

Individual trees were selected from a 7-year-old western redcedar genecology trial with open-pollinated family structure established at Holt Cr., southern Vancouver Island, British Columbia $\left(48^{\circ} 45^{\prime} \mathrm{N}, 123^{\circ} 53^{\prime} \mathrm{W}\right.$, elev. $\left.212 \mathrm{~m}\right)$. The trial was originally planted with 1 -year-old container seedlings grown from seed collected from individual trees (openpollinated families) representing each of 14 populations located throughout the natural range of western redcedar in British Columbia (BC). The design was a randomized complete block with 48 blocks (one seedling per family per block).

All trees in the genecology trial were assessed for total foliar needle monoterpenes and browse intensity. Selections were included from three putative browse categories based on these traits: non-preferred (no browse and high monoterpene content), preferred (high browse and low monoterpene content), and intermediate (low browse and average monoterpene content). Selected trees were then cloned through propagation by rooted cuttings and seed produced using controlled crossing techniques. Cloned rooted cuttings were taken from serial propagated clonal donors established from the original cuttings to minimize ontogenetical effects within and between clones on plant quality (Krakowski et al.
2005). For seedlings, seed was sown from pedigreed families. Both rooted cuttings and seedlings were grown in greenhouses according to standard nursery protocol. The resultant one-year-old rooted cuttings and seedlings were used for all subsequent experiments.

\section{Foliar monoterpene analyses}

All plant tissue collected was stored on ice while being transported to the lab for extraction and analysis. Samples were roughly chopped with scissors, placed in a liquid nitrogencooled mortar and pestle, and finely ground under liquid nitrogen. Approximately $0.400 \mathrm{~g}$ of ground sample was added to a vial and $4.00 \mathrm{ml}$ of methanol was added. The sample was extracted at room temperature for $48 \mathrm{~h}$ then transferred to a $2-\mathrm{ml}$ autosampler vial. The samples were analyzed by gas chromatography with a flame ionization detector equipped with an Agilent Ultra 2 (5\%-Phenyl-methylpolysiloxane) 25 $\mathrm{m} \times 0.2 \mathrm{~mm}$ (0.33 um thickness) column. Instrument conditions as follows: Injector and detector temperatures: $200^{\circ} \mathrm{C}$ and $300^{\circ} \mathrm{C}$; helium linear velocity: $32 \mathrm{~cm} \mathrm{~s}^{-1}$; split ratio of 35:1. Oven at: $60^{\circ} \mathrm{C}$ for $7 \mathrm{~min}$ followed by a ramp of $7^{\circ} \mathrm{C}$

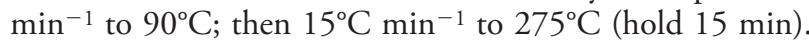
Pure analytical standards were used to identify and quantify each compound. Total monoterpene content was calculated by summation.

\section{Clonal pen trial}

To examine fine-scale deer foraging behavior within single plots, this experiment (and the following field trial) was designed to determine if browse preferences differed among western redcedar in a predictable fashion according to monoterpene content. Dormant 1-year old cloned rooted cuttings from 42 clones selected from among the three previously described preference categories were established in five pens (2.0 ha) at the USDA Olympia Field Station ( $46^{\circ} 57^{\prime} \mathrm{N}$, $122^{\circ} 58^{\prime} \mathrm{W}$, elev. $57 \mathrm{~m}$ ). Foliar total monoterpene concentrations (parts-per-million, $\mathrm{ppm}$, or $\mu \mathrm{g} \mathrm{g}^{-1}$ ) of the individual plants in the three browse preference categories were as follows: preferred $(0-15300 \mathrm{ppm})$, intermediate (16 200 - 19 $200 \mathrm{ppm})$ and non-preferred (20 $900-51300 \mathrm{ppm})$. Each category was represented by 14 clones. Individual rooted cuttings were randomly planted, one copy per clone, in each of seven contiguous replications in $7 \times 6$ arrangements with $1 \times 1 \mathrm{~m}$ spacing. Plant locations within the single plot formed by the contiguous replicates were classified as either 'interior' or 'border'. Any location in the outer two rows of the plot was considered to be in the plot border. All other locations were considered to be interior. In total, there were 150 interior locations and 144 border locations per pen.

Three captive black-tailed deer (maternal-raised) were randomly assigned to each pen immediately after planting and remained in the assigned pen for the duration of the 15-day study. Naturally occurring forbs and shrubs were well-browsed in advance of the experiments, leaving only a limited assortment of cool season grasses. Deer were provided ad libitum access to pelleted basal diet throughout the experiment. All plants were assessed for deer browse on days 1 to 7,11 and 15 . The first day that all lateral branches were visibly browsed was recorded as the failure day for that 
experimental unit. The experiment was conducted during the period of 2 to 18 February 2006 and approved by the Institutional Animal Care and Use Committee of the USDA-APHIS-WS-NWRC.

In addition to location (interior or border), spatial patterns of activity were evaluated by mapping failure day responses and phytochemical data for all individual western redcedar in each pen. Two variables were defined to describe spatial relationships among individual plants. For each plant in the single plot, 'browsecount' was the number of rooted cuttings in the second-order neighborhood (horizontally, vertically, or diagonally adjacent) with a lower failure day (i.e. previously browsed). A spatial measure of defense guilds, termed 'terpcount', was also determined for each rooted cutting. Terpcount was the number of plants in the second-order neighborhood of each plant classified in the non-preferred category (i.e. having total monoterpene content greater than 20900 ppm).

Because plants were not assessed continuously, failure response data were considered interval censored and plants that survived to the end of the experiment (did not meet definition of failure) were handled as right censored. Data were analyzed using an accelerated failure time (AFT) model using PROC LIFEREG in SAS (SAS 2004). AFT models are parametric, and each covariate impacts survival time as a constant multiplier (Hosmer et al. 2008). A graphical evaluation of cumulative hazard of the Cox-Snell residuals determined the log normal distribution to be the best fit. The model included pen, replicate (nested in pen), location, and preference category (preferred, intermediate, non-preferred) as class (categorical) effects. Continuous covariates browsecount and terpcount were inputted singly into the model and only significant covariates were retained. In addition to regression coefficients for preference categories and covariates, survivorship curves were also estimated. Pair-wise comparisons of preference category estimates were made using unadjusted Wald tests which sometimes involved manual manipulation of the estimated parameters, their variances, and their covariances (Allison 1995). Multiple comparisons were made using the false discovery rate controlling procedure (Benjamini and Hochberg 1995).

\section{Clonal field trial}

The field study was established near Cowichan Lake $\left(48^{\circ} 48^{\prime} \mathrm{N}, 124^{\circ} 39^{\prime} \mathrm{W}\right.$, elev. $\left.216 \mathrm{~m}\right)$ on south Vancouver Island, British Columbia in early February 2006. One-year old rooted cuttings from the three preference categories were established in 15 replications of 40 clones (one per replicate) at $2 \times 2 \mathrm{~m}$ spacing. All plants were assessed for deer browse on days $7,21,26,34,41,46,53,67$ and 81 . The first day that all lateral branches were visibly browsed was recorded as the failure day for that experimental unit. The experiment was conducted during the period of 9 February 2006 to 1 May 2006.

Because plants were not assessed continuously, failure data were considered interval censored and plants that survived to the end of the experiment (did not meet definition of failure) were handled as right censored. Data were analyzed using an AFT model (PROC LIFEREG; SAS 2004). A graphical evaluation of cumulative hazard of the Cox-Snell residuals determined the log normal distribution to be the best fit. The model included replicate and preference category (preferred, intermediate, non-preferred) as class (categorical) effects. Regression coefficients for the class effects and survivorship curves were estimated and unadjusted post-hoc comparisons (i.e. Wald tests) were made of preference category estimates.

\section{Plot selection trial}

A third experiment was designed to examine coarse-scale foraging behavior. Plot selection was evaluated among three plots varying in the distribution of non-preferred plants. Fifteen black-tailed deer obtained from the captive herd (maternal-raised) at the USDA Olympia Field Station $\left(46^{\circ} 57^{\prime} \mathrm{N}\right.$, $122^{\circ} 58^{\prime} \mathrm{W}$, elev $57 \mathrm{~m}$ ) were assigned to one of three test herds. Herds (identified by pen number) were maintained in separate home pens $(1,2$ or 10$)$ where they were provided pelleted food, water, mineral block, and shelter ad libitum. Herds were rotated into the 2.0 hectare test pen for overnight access to the test plots. The experiment was conducted during the period of 12 May 2008 to 24 May 2008 and approved by the Institutional Animal Care and Use Committee of the USDA-APHIS-WS-NWRC.

Three plots were created in the test pen such that the distance between them was maximized $(>50 \mathrm{~m})$. Each plot consisted of 90 seedlings planted in a $9 \times 10$ arrangement with $2.5 \times 2.5 \mathrm{~m}$ spacing. Plots consisted of 33, 66 or $100 \%$ non-preferred plants $(>35000 \mathrm{ppm}$ total monoterpenes). Preferred western redcedar $(<20000 \mathrm{ppm})$ made up the remainder of the $33 \%$ and $66 \%$ plots. Seedlings for monoterpene groups were chosen from a base population of pedigreed families such that a majority of the parents were represented across the groups while maintaining the monoterpene range established for each group.

A single herd was moved into the test pen at 16:00 hours and remained there until 08:00 the next morning; at which time the herd was moved back to the appropriate home pen. All trees in the plot were assessed for evidence of browse and a browse score was assigned $(0=$ no evidence of browse; $1=$ single bite evident; $2=$ multiple bites; $3=$ completely consumed). Plants with a browse rating of 2 and 3 were replaced with the appropriate preference category (preferred or non-preferred) and the bioassay was repeated with a second herd. A lack of seedlings precluded testing with three herds as originally designed. After both herds were exposed to the first configuration, the treatments (33, 66 and $100 \%)$ were re-assigned to new plot locations and the procedures repeated with both herds using the second configuration. The experiment was then repeated using cloned rooted cuttings and all three herds with two plot configurations (Table 1).

Seedling and rooted cutting bioassays were analyzed separately. Categorical browse response data were subjected to analysis of variance using PROC MIXED in SAS (2004). Fixed effects were: treatment $(33,66,100 \%)$, configuration $(1,2)$, and treatment $\times$ configuration. Herd and interactions with herd were modeled as random effects. Multiple comparisons were made using the false discovery rate procedure (Benjamini and Hochberg 1995).

To determine if treatment effects were purely a function of the number of low monoterpene plants in each treatment (i.e. deer simply ate the preferred, low monoterpene 
Table 1. Treatment assignments (distribution of non-preferred trees) for experimental configurations of the western redcedar plot selection bioassay.

\begin{tabular}{llrrrrr}
\hline Day & Trees & Herd & Configuration & Plot A & Plot B & Plot C \\
\hline 1 & seedlings & 1 & 1 & $100 \%$ & $33 \%$ & $66 \%$ \\
2 & seedlings & 2 & 1 & $100 \%$ & $33 \%$ & $66 \%$ \\
3 & seedlings & 2 & 2 & $66 \%$ & $100 \%$ & $33 \%$ \\
4 & seedlings & 1 & 2 & $66 \%$ & $100 \%$ & $33 \%$ \\
5 & rooted cuttings & 10 & 3 & $33 \%$ & $66 \%$ & $100 \%$ \\
6 & rooted cuttings & 1 & 3 & $33 \%$ & $66 \%$ & $100 \%$ \\
7 & rooted cuttings & 2 & 3 & $33 \%$ & $66 \%$ & $100 \%$ \\
8 & rooted cuttings & 10 & 1 & $100 \%$ & $33 \%$ & $66 \%$ \\
9 & rooted cuttings & 1 & 1 & $100 \%$ & $33 \%$ & $66 \%$ \\
10 & rooted cuttings & 2 & 1 & $100 \%$ & $33 \%$ & $66 \%$ \\
\hline
\end{tabular}

plants in each plot and moved to the next) frequency tables were generated for each treatment using browse response and monoterpene classification (low, high). A CochranMantel-Haenszel (CHM) test was performed (PROC FREQ; SAS 2004) to test the null hypothesis that browse response was independent of preference category within each treatment level.

\section{Results}

\section{Clonal pen trial}

A high percentage of cloned rooted cuttings were browsed during the 15 -day study (82.2\%). However, survivability distributions varied significantly among the three preference categories $(p=0.0003$, Fig. 1). The failure response was significantly impacted by the class effects pen and replicate $(\mathrm{p}<0.0001)$ as well as the spatial effects browsecount and location $(\mathrm{p}<0.0001)$. The measure of defense guild, terpcount, was not significant $(\alpha=0.05)$. Preferred plants were browsed (i.e. failed) faster than intermediate $(\mathrm{p}=0.005)$ or non-preferred ones $(p<0.0001)$. There was no significant difference between non-preferred and intermediate western redcedar $(p=0.28)$. Preferred rooted cuttings failed at a rate $9.8 \%$ greater than intermediate and $13.9 \%$ faster than non-preferred. The failure rate of interior plants was $14.9 \%$ greater than those on the border. For every previously failed rooted cutting in the second-order neighborhood of a surviving plant (browsecount), there was a $24.3 \%$ reduction in failure rate.

\section{Clonal field trial}

A lower percentage of cloned rooted cuttings were browsed during the 15 -week field study $(13.8 \%)$ as compared to the pen trial. Similar to the pen trial, survivability distributions varied significantly among the three western redcedar preference categories $(p<0.0001$, Fig. 2). Preferred rooted cuttings failed at faster rate than intermediate $(p<0.0001)$ and non-preferred plants $(p=0.0003)$. There was no significant difference in failure rates between intermediate and nonpreferred rooted cuttings $(p=0.31)$. Preferred plants failed 2.7 times faster than intermediate plants and 4.0 times faster than non-preferred.

\section{Plot selection trial}

For seedlings, all fixed effects were significant - including treatment $(\mathrm{p}<0.0001$, Fig. 3). Browse responses decreased with increasing percentage of non-preferred seedlings: $33 \%>66 \%>100 \%$ (mean browse scores were 1.90, 1.36 and 1.00 respectively). The significant treatment $\times$ configuration effect indicated a plot preference. However, this is confounded by the incomplete design (e.g. plot $\mathrm{C}$ never received the $100 \%$ treatment which likely would have significantly lowered browse mean in this plot). Within treatments, browsing was independent of preference category indicating that deer did not browse lower proportions of non-preferred seedlings than expected by chance encounter (Fig. 4, $\mathrm{p}=0.964$ ).

There was substantially less browsing activity when cloned rooted cuttings were offered to the deer (overall mean browse score for rooted cuttings was 0.49 vs 1.27 for seedlings). As with seedlings, all fixed effects were significant for rooted cuttings ( $\mathrm{p}<0.0001$ ). Both $33 \%$ and $66 \%$ treatments were more

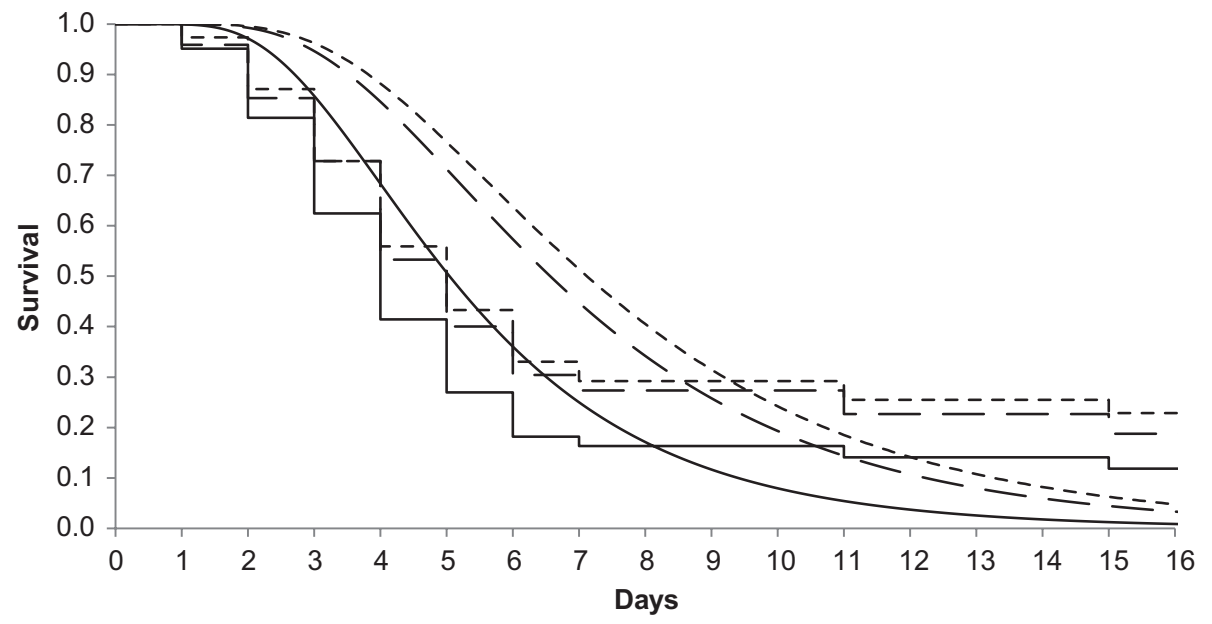

Figure 1. Survivability curves of rooted cuttings categorized as preferred, intermediate, or non-preferred in the western redcedar clonal pen trial. Jagged lines are the cumulative proportion of browsed plants and smooth curves are model-estimated survival. Legend: — preferred preference category; -- intermediate preference category; $\cdots \cdots$ non-preferred preference category. 


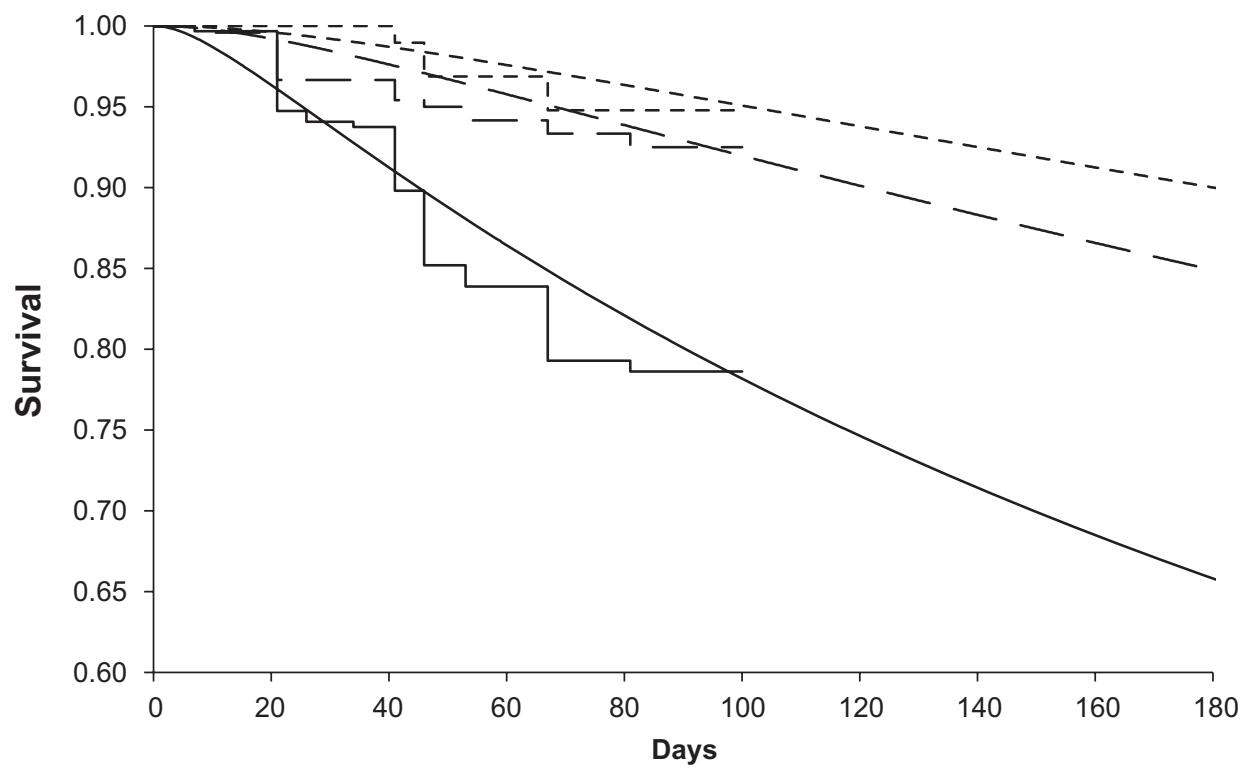

Figure 2. Survivability curves of rooted cuttings categorized as preferred, intermediate, or non-preferred in the western redcedar clonal field trial. Jagged lines are the cumulative proportion of browsed plants and smooth curves are model-estimated survival. Legend: - preferred preference category; - - intermediate preference category; $\cdots \cdots$ non-preferred preference category

heavily browsed than the $100 \%$ treatment, though browsing did not differ between them $(\mathrm{p}=0.16)$. A significant treatment $\times$ configuration effect indicated a plot effect with rooted cuttings, as browse scores were greater in both plots A and B versus plot $\mathrm{C}$. As with seedlings, this was confounded by the incomplete design. Unlike the seedlings, within-treatment discrimination was observed $(\mathrm{p}<0.0001)$ indicating that deer browsing of non-preferred rooted cuttings was significantly less than would be expected by chance.

\section{Discussion}

Herbivory has the potential to alter plant diversity at multiple scales (Provenza et al. 2003). The present experiments were designed to provide deer a suite of ecologically-relevant phytochemical cues in controlled environments. Not only did this allow monitoring of deer preference for specific phytochemical cues, but also examination of spatial aspects of deer browse behavior. Three factors were presumed to influence deer browsing at multiple scales in these experiments: 1) palatability of the targeted browse item;2) availability of the targeted browse item; and 3) neighbor effects. Because these experiments employed plants of the same age and species grown under identical environmental conditions, differences in palatability among individuals were likely driven exclusively by PSM content. Total monoterpene concentration was used to define PSM content because of the strong correlations among individual monoterpenes identified in

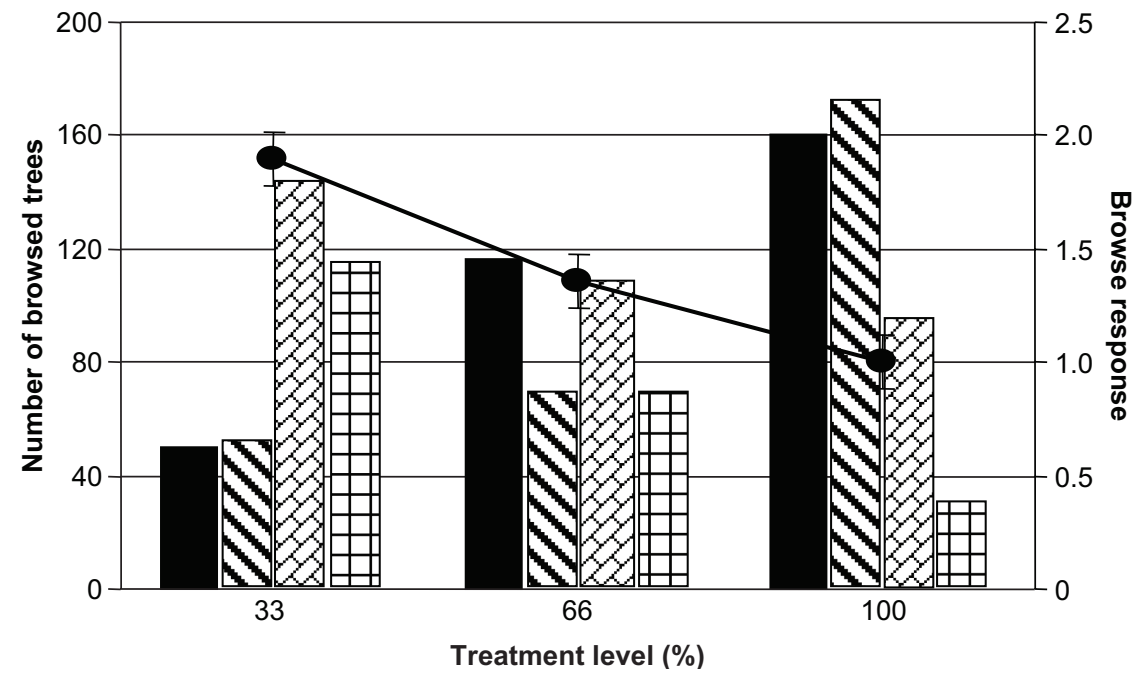

Figure 3. Frequency of seedlings browsed in plots of 33\%, 66\% or 100\% non-preferred western redcedar and resultant mean browse response. Mean browse response is an overall treatment least-square mean with error bars representing one standard error. Legend: $\mathbf{\square}$ no browse (0); $\mathbf{\$}$ minor browse (1); $\square$ moderate browse (2); 国 severe browsing (3); mean browse response. 


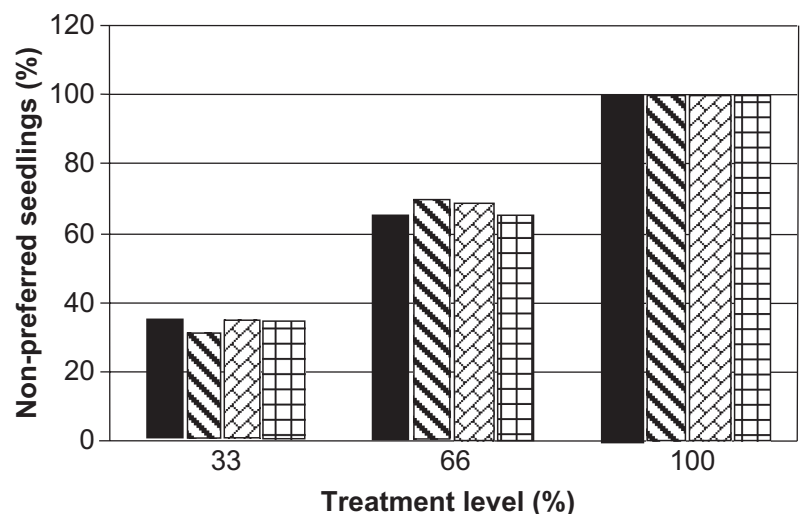

Figure 4. Percentage of non-preferred seedlings browsed in plots of $33 \%, 66 \%$ or $100 \%$ non-preferred western redcedar for both configurations. Legend: $\square$ no browse (0); $\mathbf{W}$ minor browse (1); moderate browse (2); 团 severe browsing (3).

western redcedar foliage (Kimball et al. 2011). Use of total monoterpenes (or artificial mixtures of several monoterpenes) has also been employed in many previous studies of foraging behavior (Duncan et al. 1994, Villalba et al. 2002, Villalba and Provenza 2005, Dziba and Provenza 2008).

\section{Palatability}

From an herbivore's perspective, individual plants contain both beneficial and deleterious phytochemicals that define plant palatability and impact diet selection. By integrating the flavor of foods with the postingestive consequences of consuming them, herbivores learn to limit intake of PSMs (Villalba and Provenza 2005). Furthermore, experience with one class of PSMs impacts herbivore intake of other classes of plant defenses (Villalba et al. 2004, Kimball and Nolte 2005). Affective learning processes yield preferences and aversions for particular diets that are further subject to cognitive associations with other sensory or contextual attributes of the food (Provenza et al. 1992). Learned preferences and aversions to food odors are thought to progress through elementary taste aversions.

Olfaction is likely to represent a reliable tool for herbivores to assess the monoterpene content of conifers owing to relatively high vapor pressures. Deer responses to individual monoterpenes were previously shown to be correlated to the vapor pressure of individual monoterpenes (Elliott and Loudon 1987). Although release of plant volatiles is under physiochemical control, particularly stomatal conductance (Niinemets et al. 2002), vapor phase measurements of monoterpenes are highly correlated with tissue monoterpene concentrations (Schafer et al. 1995). Thus, increased quantities of monoterpenes in plant foliage are reflected in the vapor emanating from the plant. Furthermore, monoterpene emissions from conifers with indeterminate needle growth, such as western redcedar, are relatively stable with relatively little diurnal variation and only moderate seasonal variation (Yatagai et al. 1995). Thus, phytochemical assessment of individual plants may be achieved by olfaction permitting herbivores to assess monoterpene content of conifers and make assessments of forage quality without having to consume the plant.

\section{Availability}

Plant height and species abundance contribute to the availability of focal plants (Miller et al. 2007). In this single species study with homogeneous age structure, we used the spatial parameter browsecount as a measure of availability. Within a plot, the probability of a particular plant being browsed decreased significantly when it was in close proximity to other plants that had been previously browsed. Thus, selection of individual plants was influenced by presence or absence of its neighbors. In this manner, fine-scale foraging decisions yield heterogeneity observable at greater scale. Access to individual plants has similar impact. For example, our results also indicated that rooted cuttings located in plot interiors were more likely to be browsed than those planted in the border, likely owing to increased number of accessible plants in the finite foraging area. At greater scales, deer have also been shown to forage in forest interiors (Cadenasso and Pickett 2000). However, these edge effects incorporate species interactions, edge depths, and resource distributions not assessed in the present study (Ries et al. 2004).

\section{Neighboring plants}

In heterogeneous patches, the palatability and availability of neighboring plants significantly impacts vulnerability of individual plants to herbivory (Miller et al. 2007). The variable terpcount was used to assess the effect of neighboring phytochemistry on diet selection. The theory of defense guilds predicts that the presence of highly defended individuals will render that specific location unfit for foraging and confer a measure of defense to all plants in the localized area (Atsatt and Odowd 1976). In a forage manipulation study, presence of unpalatable plants was shown to reduce browsing of spruce by cows and horses (Smit et al. 2006). However, associational protection from neighboring plants is more likely to be expressed when herbivores are selective at coarse scales (Tuomi and Augner 1993). Other studies have demonstrated that plot selection is strongly influenced by quality factors such as species variability and the proportion of unpalatable plants. In one such study, mammalian herbivory of Norway spruce Picea abies was much higher in plots without unpalatable plants (Smit et al. 2006). The authors suggest planting unpalatable plants as a strategy for protecting desirable plant species. Evaluation of the failure response in the clonal pen trial suggests that having highly defended plants in close proximity to individual clones did not impact browse preference - indicating that highly defended conspecifics did not constitute a defense guild.

\section{Within plot diet selection behavior}

Diet selection by deer among several plant species can be influenced by both fine and coarse scale foraging decisions (Bergman et al. 2005). Within-plots, captive deer selected manipulated diets in a manner that limited tannin intake within-plots, whereas between-plot behavior was not affected (Bergvall and Leimar 2005, Bergvall et al. 2006). In these experiments, deer were assumed to employ a 'momentary maximization' strategy while selecting plants for browse (Senft et al. 1987). Momentary maximization predicts that 
individuals will forage in finite areas with limited locomotion as they assess forage quality. Large herbivores select the most palatable plants or plant parts that are within reach until the quality of remaining forage within the finite area decreases to a threshold value - at which point the herbivore moves to a new foraging location (Bailey et al. 1996). Thus, diet selection (which individual plants are browsed) can be explained by constraints in energy intake rate enforced by the spatial arrangement of neighboring plants (Courant and Fortin 2010).

Phytochemical content of individual rooted cuttings influenced deer browse preference. In particular, those clones with highest concentrations of the monoterpenes (nonpreferred) were less likely to be browsed. This is consistent with previous studies conducted with deer (Elliott and Loudon 1987, Vourc'h et al. 2002a, b). Monoterpenes are considered antifeedants, or quantitative defenses, that are present in large quantities in plants and reduce the palatability of foods. The impact of individual monoterpene content was much more evident in the field trial. While nonpreferred, high-monoterpene clones disappeared fairly rapidly in the pen trial; they were far less likely to be browsed in the field trial. These differences probably reflect a significantly greater likelihood of encounter and browsing by captive deer during the15-day pen trial as compared to the encounter rate of free-ranging deer during the 81-day field trial. In addition, free-ranging deer were able to locate additional foraging areas as more preferred plant species became available in the early summer. Overall, browse damage was much greater in the pen trial $(82.2 \%)$ versus the field trial (13.8\%). Importantly, the similar results of the two experiments demonstrate that deer selection of individual cloned rooted cuttings was significantly influenced by monoterpene content.

\section{Plot selection behavior}

Although no protective effects of highly defended neighbors were observed in fine-scale foraging (selection of individual plants), a protective effect was observed at the coarser scale. For both seedlings and cloned rooted cuttings in the plot selection trial, deer made plot selections based on the distribution of monoterpenes. Higher proportions of nonpreferred plants reduced browsing in the plot as a whole. Although olfactory information regarding PSM content of the plants may have been acquired during fine-scale diet selection, it remains possible olfactory information allowed deer to assess distributions of high monoterpene-content plants without need for foraging in the plots. Duncan et al. (1994) concluded that red deer Cervus elaphus did not rely on olfaction to identify palatable Sitka spruce Picea sitchensis trees in an experiment similar to our clonal pen trial. This is likely a product of the study design and frequency of measuring browse responses. Consequently, it is not possible to consider the role of olfaction in diet selection of individual redcedar plants in the clonal pen trial. However, a plausible explanation for observed responses in the plot selection trial is that forage quality differences among the three plots were assessed by olfaction. Certainly, further research is needed to determine the importance of olfaction in large-scale (e.g. plot selection) foraging behavior.
It has been demonstrated that variability of resource distributions can have profound effects on learning and foraging behavior (van der Post and Hogeweg 2006). While many studies have shown that herbivores remain in a specific patch until the instantaneous intake rate diminishes with respect to the attainable rate among all patches according to the marginal value theorem (Charnov 1976), others have found that residence time in a plot is greater than predicted by theory (Searle et al. 2005). Although residence time was not measured in the current study, foraging investment as determined by extent of browse activity was significantly influenced by distributions of PSMs in the available plots. These results suggest that deer qualitatively employ a risk-averse foraging strategy (Kacelnik and Bateson 1996). Risk-reward foraging has not been extensively studied with large herbivores. However, avoidance of novel and/or strong flavors by lambs has been attributed to a risk-aversive foraging strategy (Augner et al. 1998). Studies with rodents have been more prevalent. Among them, lemmings were shown to prefer patches with predictable resources (Searle et al. 2006). In this study, deer similarly used learned information regarding food quality to forage preferentially in plots that minimized exposure to monoterpenes.

\section{Multi-scale observations}

Because foraging responses from both within- and amongplot experiments were determined by measuring browse activity on individual plants (a fine-scale measurement), it is possible that observed plot preferences were merely an artifact of fine-scale foraging strategies. In other words, plot preferences could merely result from deer preferentially browsing poorly defended plants in each plot. However, evaluation of the data from the plot selection trial conducted with seedlings indicated that plot preferences resulted from coarsescale foraging decisions. Within available plots, browsing of low monoterpene-content seedlings was not greater than expected by chance. While this within-plot behavior was in contrast to clonal pen and field trials where discrimination was observed among individual plants, it does not necessarily follow that plot characteristics are more predictive of browse activity than individual plant phytochemistry. Finescale browse behavior may have differed among these studies because of experimental differences such as plant availability (294 rooted cuttings in the contiguous blocks for the clonal pen trial, 600 in the field trial, and 90 per plot in the plot selection experiment), plant spacing $(1 \mathrm{~m}, 2 \mathrm{~m}$ and $2.5 \mathrm{~m}$, respectively), plant type (cloned rooted cuttings and seedlings), or any combination of these factors. In fact, there was evidence of within-plot plant discrimination in the plot selection trial when rooted cuttings were deployed such that browsing of high monoterpene-content rooted cuttings was significantly lower than would be expected by chance.

The relative aspect of phytochemical influence on diet selection is also evident from these experiments. Deer demonstrated preferences for individual plants with lower concentrations of foliar monoterpene as compared to those available in the same plot or in adjacent plots. In the clonal pen and feed trials, deer preferred individual cuttings with monoterpene concentrations less than 15300 ppm (preferred category), while no differences were observed among 
so-called intermediate (16 $200-19200$ ppm) and nonpreferred (20 $900-51300 \mathrm{ppm})$ cuttings. These observations were likely driven by contrasting monoterpene concentrations, not an absolute threshold value. In fact, the concentration ranges of plants in the preferred $(<20000$ $\mathrm{ppm})$ and non-preferred $(>35000 \mathrm{ppm})$ plants employed in the plot selection trial need not match the concentrations used to define categories in the clonal pen and field trials. Rather, relative preferences result among all contrasting monoterpene concentrations up to an undetermined threshold at which detoxification costs exceed the benefits of consumption (Iason and Villalba 2006).

The inability to detect within-plot selection of seedlings may be a product of increased preference for seedlings versus rooted cuttings. Disappearance of preferred seedlings may have proceeded at a rate imperceptible to the frequency of measurement in the plot selection trial. Although not tested explicitly, a considerable difference in browse preference was observed between seedlings and rooted cuttings. Declining photosynthetic rates and nutritional quality associated with maturation and senescence has been studied in conifers (Hempfling et al. 1991, Warren 2006). Although nitrogen can be variable (studies have shown both increased and decreased foliar nitrogen with maturation), decreased carbohydrate and increased lignin content accompanies tissue maturation in conifers. These physiological changes are likely to affect tactile and nutritional qualities as well as water content. Specifically in deer, reduced browse quality associated with plant tissue maturation has been attributed to lignification (Stewart et al. 2000). Like monoterpenes (Huber et al. 2004), lignin production in vascular plants is under genetic control (Moore and Jung 2001). Further study of ontogenetic factors related to deer browse behavior may yield significant information regarding diet selection by large herbivores.

Acknowledgements - Assistance from Craig Ferguson (CLRS) propagating plants and establishing the field trial as well as planting assistance from Suzie Rizor, Julie Maenhout, Kelly Perry and Sean Lamb (NWRC) in pen trials was greatly appreciated. Chemical analyses were performed under contract by Clive Dawson and Dave Dunn (Ministry of Forests and Range North Road lab). Mention of specific products does not constitute endorsement by the US Dept of Agriculture or BC Ministry of Forests and Range. The authors thank Drs. Larry Howery and Susan Shriner for comments on previous drafts of the manuscript.

\section{References}

Allison, P. D. 1995. Survival analysis using the SAS System: a practical guide. - SAS Inst.

Atsatt, P. R. and Odowd, D. J. 1976. Plant defense guilds. - Science 193: 24-29.

Augner, M. et al. 1998. A rule of thumb in mammalian herbivores? - Anim. Behav. 56: 337-345.

Bailey, D. W. et al. 1996. Mechanisms that result in large herbivore grazing distribution patterns. - J. Range Manage. 49: 386-400.

Bee, J. et al. 2009. The benefits of being in a bad neighbourhood: plant community composition influences red deer foraging decisions. - Oikos 118: 18-24.

Bell, C. M. and Harestad, A. S. 1987. Efficacy of pine oil as repellent to wildlife. - J. Chem. Ecol. 13: 1409-1417.
Benjamini, Y. and Hochberg, Y. 1995. Controlling the false discovery rate - a practical and powerful approach to multiple testing. - J. R. Stat. Soc. B Methodol. 57: 289-300.

Bergman, M. et al. 2005. Feeding patterns by roe deer and rabbits on pine, willow and birch in relation to spatial arrangement. - Oikos 109: 513-520.

Bergvall, U. A. and Leimar, O. 2005. Plant secondary compounds and the frequency of food types affect food choice by mammalian herbivores. - Ecology 86: 2450-2460.

Bergvall, U. A. et al. 2006. Associational effects of plant defences in relation to within- and between-patch food choice by a mammalian herbivore: neighbour contrast susceptibility and defence. - Oecologia 147: 253-260.

Bryant, J. P. et al. 1991. Interactions between woody-plants and browsing mammals mediated by secondary metabolites. - Annu. Rev. Ecol. Syst. 22: 431-446.

Bryant, J. P. et al. 1992. Chemically mediated interactions between woody-plants and browsing mammals. - J. Range Manage. 45: $18-24$.

Cadenasso, M. L. and Pickett, S. T. A. 2000. Linking forest edge structure to edge function: mediation of herbivore damage. - J. Ecol. 88: 31-44.

Carmona, D. et al. 2011. Plant traits that predict resistance to herbivores. - Funct. Ecol. 25: 358-367.

Charnov, E. L. 1976. Optimal foraging, marginal value theorem. - Theor. Popul. Biol. 9: 129-136.

Courant, S. and Fortin, D. 2010. Foraging decisions of bison for rapid energy gains can explain the relative risk to neighboring plants in complex swards. - Ecology 91: 1841-1849.

Dearing, M. D. et al. 2002. Ingestion of plant secondary compounds causes diuresis in desert herbivores. - Oecologia 130: 576-584.

Dimock, E. J. et al. 1976. Genetic resistance in douglas-fir to damage by snowshoe hare and black-tailed deer. - For. Sci. 22: $106-121$.

Duncan, A. J. et al. 1994. The effect of monoterpene concentrations in Sitka spruce (Picea sitchensis) on the browsing behavior of red deer (Cervus elaphus). - Can. J. Zool. 72: $1715-1720$.

Dziba, L. E. and Provenza, F. D. 2008. Dietary monoterpene concentrations influence feeding patterns of lambs. - Appl. Anim. Behav. Sci. 109: 49-57.

Elliott, S. and Loudon, A. 1987. Effects of monoterpene odors on food selection by red deer calves (Cervus elaphus). - J. Chem. Ecol. 13: 1343-1349.

Estell, R. E. et al. 1998. Relationship of tarbush leaf surface terpene profile with livestock herbivory. - J. Chem. Ecol. 24: 1-12.

Farentinos, R. C. et al. 1981. Selective herbivory in tassel-eared squirrels - role of monoterpenes in ponderosa pines chosen as feeding trees. - Science 213: 1273-1275.

Goralka, R. J. L. et al. 1996. Variation in chemical and physical properties during leaf development in California Bay tree (Umbellularia californica): predictions regarding palatability for deer. - Biochem. Syst. Ecol. 24: 93-103.

Hempfling, R. et al. 1991. Characterization and chemodynamics of plant constituents during maturation, senescence and humus genesis in spruce ecosystems. - Biogeochemistry 13: $27-60$.

Hobbs, N. T. 1996. Modification of ecosystems by ungulates. - J. Wildlife Manage. 60: 695-713.

Hobbs, N. T. et al. 2003. Herbivore functional response in heterogeneous environments: a contest among models. - Ecology 84: 666-681.

Hosmer, D. W. et al. 2008. Applied survival analysis, regression modelling of time-to-event data. - Wiley.

Huber, D. P. W. et al. 2004. Genomic hardwiring and phenotypic plasticity of terpenoid-based defenses in conifers. - J. Chem. Ecol. 30: 2399-2418. 
Iason, G. R. and Villalba, J. J. 2006. Behavioral strategies of mammal herbivores against plant secondary metabolites: the avoidance-tolerance continuum. - J. Chem. Ecol. 32: 1115-1132.

Kacelnik, A. and Bateson, M. 1996. Risky theories - the effects of variance on foraging decisions. - Am. Zool. 36: 402-434.

Kimball, B. A. and Nolte, D. L. 2005. Herbivore experience with plant defense compounds influences acquisition of new flavor aversions. - Appl. Anim. Behav. Sci. 91: 17-34.

Kimball, B. A. et al. 1998. Chemically mediated foraging preference of black bears (Ursus americanus). - J. Mammal. 79: 448-456.

Kimball, B. A. et al. 2011. Silvicultural attempts to induce browse resistance in conifer seedlings. - Int. J. For. Res. id 108529.

Koricheva, J. et al. 1998. Regulation of woody plant secondary metabolism by resource availability: hypothesis testing by means of meta-analysis. - Oikos 83: 212-226.

Krakowski, J. et al. 2005. Effects of serial propagation, donor age, and genotype on Chamaecyparis nootkatensis physiology and growth traits. - Can. J. For. Res. 35: 623-632.

Manier, D. J. and Hobbs, N. T. 2006. Large herbivores influence the composition and diversity of shrub-steppe communities in the Rocky Mountains, USA. - Oecologia 146: 641-651.

Miller, A. M. et al. 2007. Effects of within-patch characteristics on the vulnerability of a plant to herbivory. - Oikos 116: 41-52.

Miyazawa, M. et al. 1997. Inhibition of acetylcholinesterase activity by monoterpenoids with a p-menthane skeleton. - J. Agric. Food Chem. 45: 677-679.

Moore, K. J. and Jung, H. J. G. 2001. Lignin and fiber digestion. - J. Range Manage. 54: 420-430.

Niinemets, U et al. 2002. Stomatal constraints may affect emission of oxygenated monoterpenoids from the foliage of Pinus pinea. - Plant Physiol. 130: 1371-1385.

O'Reilly-Wapstra, J. M. et al. 2005. Effects of nutrient variability on the genetic-based resistance of Eucalyptus globulus to a mammalian herbivore and on plant defensive chemistry. Oecologia 142: 597-605.

Provenza, F. D. et al. 1992. Mechanisms of learning in diet selection with reference to phytotoxicosis in herbivores. - J. Range Manage. 45: 36-45.

Provenza, F. D. et al. 2003. Foraging by herbivores: linking the biochemical diversity of plants with herbivore culture and landscape diversity. - In: Bisonette, J. A. and Storch, I. (eds), Landscape ecology and resource management: linking theory with practice. Island Press, pp. 387-422.

Reichardt, P. B. et al. 1990. Winter chemical defense of alaskan balsam poplar against snowshoe hares. - J. Chem. Ecol. 16: 1941-1959.

Rhoades, D. F. 1979. Evolution of plant chemical defense against herbivores. - In: Rosenthal, G. A. and Janzen, D. H. (eds), Herbivores. Their interaction with secondary plant metabolites. Academic Press, pp. 3-54.
Ries, L. et al. 2004. Ecological responses to habitat edges: mechanisms, models, and variability explained. - Annu. Rev. Ecol. Evol. Syst. 35: 491-522.

Schafer, B. et al. 1995. Analysis of monoterpenes from conifer needles using solid-phase microextraction. - J. High Resolut. Chromatogr. 18: 587-592.

Searle, K. R. et al. 2005. Should I stay or should I go? Patch departure decisions by herbivores at multiple scales. - Oikos 111: 417-424.

Searle, K. R. et al. 2006. Preference in patchy landscapes: the influence of scale-specific intake rates and variance in reward. Behav. Ecol. 17: 315-323.

Senft, R. L. et al. 1987. Large herbivore foraging and ecological hierarchies. - Bioscience 37: 789-799.

Smit, C. et al. 2006. Unpalatable plants facilitate tree sapling survival in wooded pastures. - J. Appl. Ecol. 43: 305-312.

Snyder, M. A. 1992. Selective herbivory by Aberts squirrel mediated by chemical variability in ponderosa pine. - Ecology 73 : 1730-1741.

Stewart, K. M. et al. 2000. White-tailed deer use of clearings relative to forage availability. - J. Wildlife Manage. 64: 733-741.

Tuomi, J. and Augner, M. 1993. Synergistic selection of unpalatability in plants. - Evolution 47: 668-672.

van der Post, D. J. and Hogeweg, P. 2006. Resource distributions and diet development by trial-and-error learning. - Behav. Ecol. Sociobiol. 61: 65-80.

Villalba, J. J. and Provenza, F. D. 2005. Foraging in chemically diverse environments: energy, protein, and alternative foods influence ingestion of plant secondary metabolites by lambs. - J. Chem. Ecol. 31: 123-138.

Villalba, J. J. et al. 2002. Consequences of the interaction between nutrients and plant secondary metabolites on herbivore selectivity: benefits or detriments for plants? - Oikos 97: 282-292.

Villalba, J. J. et al. 2004. Experience influences diet mixing by herbivores: implications for plant biochemical diversity. Oikos 107: 100-109.

Vourc'h, G. et al. 2002a. Monoterpene effect on feeding choice by deer. - J. Chem. Ecol. 28: 2411-2427.

Vourc'h, G. et al. 2002b. Disentangling the causes of damage variation by deer browsing on young Thuja plicata. - Oikos 98: 271-283.

Wang, G. M. et al. 2006. Spatial and temporal variability modify density dependence in populations of large herbivores. - Ecology 87: 95-102.

Warren, C. R. 2006. Why does photosynthesis decrease with needle age in Pinus pinaster? - Trees - Structure Funct. 20: 157-164.

Yatagai, M. et al. 1995. Seasonal variations of terpene emission from trees and influence of temperature, light and contact stimulation on terpene emission. - Chemosphere 30: 1137-1149. 